\title{
ELECTROMAGNETIC COILGUN LAUNCHER FOR SPACE APPLICATIONS
}

\author{
B. N. Turman and R.J. Lipinski \\ Sandia National Laboratories, Albuquerque, New Mexico,87185-58fR T 111995 \\ Abstract
}

A ground-based electrically-powered launcher could significantly reduce the complexity and cost of space launches for moderate-weight payloads. The EM launch complex could greatly reduce the amount of fuels handling, reduce the turn-around time between launches, allow more concurrence in launch preparation, reduce the manpower requirements for launch vehicle preparation and increase the reliability of launch by using more standardized vehicle preparations. The launch requires high acceleration, so the satellite package must be hardened. This paper presents results of a study to estimate the required launcher parameters, and estimate the cost of such a launch facility. This study is based on electromagnetic gun technology which is constrained to a coaxial geometry to take advantage of the efficiency of closely-coupled coils. The launcher energy and power requirements fall in the range of $40-260 \mathrm{GJ}$ and $20-400 \mathrm{GW}$ electric. Parametric evaluations have been conducted with a launcher length of $1-2 \mathrm{~km}$, exit velocity of $1-6 \mathrm{~km} / \mathrm{s}$, and payloads to low earth orbit of 100 $1000 \mathrm{~kg}$.

\section{INTRODUCTION}

The use of an electromagnetic launcher for propelling small satellites to orbit has the potential for greatly reducing the cost and complexity of space launch. An electromagnetic launcher, which produces a high initial launch velocity, could reduce the size of the launch vehicle by essentially replacing the first and second stages of a conventional booster. A launcher facility has the additional advantage of being fully reusable and quickly prepared for the next launch. The most efficient use of the launcher is to operate at an exit velocity in the range of $6 \mathrm{~km} / \mathrm{s}$, with a solid-motor booster stage to achieve final orbit. Delivering a payload into space poses many challenges. The most challenging are: (1) thermal management of the projectile while going through the densest portion of the atmosphere at an extremely high speed; (2) power switching and cost of energy storage, (3) mechanical and electrical stresses on coils. Less critical challenges are: (1) energy loss of the projectile while it is going through the atmosphere; (2) sonic effects on both the environment and the projectile itself; (3) stability and control of the vehicle (projectile); (4) the ability for the vehicle to rendezvous with targets already in orbit; and (5) cost effectiveness.

Electromagnetic launch should prove cost-effective for any application which requires frequent launch of small payloads, provided the payloads can be hardened against the acceleration of launch. A launcher aimed for high orbital inclination $\left(>45^{\circ}\right)$ would be suitable for deployment and replenishment of constellations of low-earth orbit communication satellites, "over-night" delivery of small packages to the space station, launch of station-keeping fuel and other supplies for the space station, and launch of low-altitude rapid-response military sensors or environmental monitors. There are already three communication constellations being developed and deployed [Jane's 1993]: Orbcomm (Orbital Sciences Corporation) will consist of 26 satellites, $45 \mathrm{~kg}$ each, at $785-\mathrm{km}$ altitude and $45^{\circ}$ inclination. Iridium (Motorola) will consist of 66 satellites, $689 \mathrm{~kg}$ each, at $765 \mathrm{~km}$ altitude and about $90^{\circ}$ inclination, with a design life of 5 years. Teledesic Corporation is planning for a constellation of 840 satellites. Replenishment of these systems and deployment of new systems could be a coilgun mission.

An east-facing launcher would be suitable for launching nuclear waste for disposal on the back side of the moon, and for launching miniature probes to inventory near-earth asteroids. The Commercial Space Transport Study (CSTS) suggested that disposal of high-level nuclear waste on the back side of the moon would be an attractive solution to the waste problem from nuclear power plants (Andrews 1994), if the cost of launch from earth to lowearth orbit (LEO) could be reduced to around $\$ 1300 / \mathrm{kg}$. A coilgun could be used as part of such an architecture. The coilgun would launch moderate-sized packages into LEO. These packages would be collected by a robotic tug which would deliver it to lunar orbit. At the moon, the waste packages would be transferred to a small lunar shuttle which would land in a large crater, deposit the waste packages there, and return to lunar orbit. The tug also would deliver the fuel for the lunar shuttle with each trip. The tug would return to LEO to pick up more waste 


\section{DISCLAIMER}

Portions of this document may be illegible electronic image products. Images are produced from the best available original document. 
canisters. The coilgun also would launch fuel for the space tug. The system would be most efficient if the tug were nuclear powered and the thrusters were electric with a high specific impulse. Ion thrusters using xenon fuel is one good option.

Use of a coilgun launcher for disposal of nuclear waste to space has several attractive features. The payload is already hardened against acceleration. The amount of inventory in each launch would be fairly small, so failure of a single launch would not be catastrophic. Indeed, the packaging would be such that no release of radioactivity would be expected even with launch failure. The launches could be done in a series of volleys, and the first few shots of each volley could be "warm-up" shot to demonstrate that all systems are working as expected. This would greatly improve the reliability of the shots which contained actual radioactive waste. Finally, the large number of shots required for nuclear waste disposal would be ideally matched with the economics of coilgun launchers where the initial investment is high, but the operational costs are very low.

The U.S. generates spent fuel rods containing 2200 tons of heavy metal (uranium plus plutonium) per year (2200 tHM/yr) [Spent Fuel 1994]. It would be economically unfeasible to launch this mass directly. But if the rods were reprocessed, the resulting amount of high-level waste would be reduced by a factor of 30 . European facilities in France and England presently reprocess spent fuel at a rate of over $2000 \mathrm{tHM} / \mathrm{yr}$. The high-level waste is separated out and vitrified. If instead of vitrifying the waste, it could be packaged in a suitable container, it would be ready for coilgun launch to space.

The CSTS notes that the modules of the General Purpose Heat Source (GPHS) used in the Galileo, Ulysses, and Cassini radioisotope thermal generators (RTGs) might be the ideal container. Each consists of two separate impact shells inside an aeroshell, with the radionuclides inside the impact shells. They have been designed and proven to survive impact on concrete at terminal velocity $(50 \mathrm{~m} / \mathrm{s})$. Regulatory approval for launch of 87,000 Curies of $\mathrm{Pu}^{238}$ in these containers on the Galileo satellite was obtained, and the successful launch occurred October 18, 1989. Successful launch of 44,000 Curies on the Ulysses satellite occurred on October 6, 1990. Launch of 131,000 Curies on Cassini is scheduled for 1997 [Ulrich 1994]. If waste disposal is proven to be economically viable, this could be a significant mission for a coilgun.

The coilgun also could be used to launch numerous simple probes to near-earth asteroids to map them and identify their mineral and water content. The probes could be a scaled-down version of the $220-\mathrm{kg}$ Clementine spacecraft which performed a similar mission for the moon in 1994 [Jane's 1994]. Keeping the probes simple and compact will enable them to be made cheaply and acceleration-hardened. There are estimated to be over 300,000 asteroids larger than 100 meters in diameter with orbits that cross earth's orbit [Langreth 1992]. This population has potential commercial value in the long run because they are an enormous supply of raw materials outside the gravity well of the earth or the moon. Obtaining an inventory of these asteroids is the first step to utilizing this resource, and a coilgun launch may enable inexpensive and rapid acquisition of such an inventory.

\section{ELECTROMAGNETIC COILGUN LAUNCHER}

An electromagnetic coilgun is an attractive option for the electrically powered launcher because it accelerates its payload without a tight, abrasive fit in the barrel, and without direct electrical contact that generates arcing. A coilgun operates by inductive forces. It consists of a series of solenoidal coils which are energized at the appropriate time by computer control. Figure 1 shows a longitudinal cross-section of the armature and surrounding solenoidal coils. The armature which pushes the flight package is a thick-walled aluminum cylinder and may have an internal shell of graphite epoxy or ceramic for compressive strength. When a coil is energized with the armature inside it, the rising magnetic field induces a circular current in the armature. The interaction of the armature current with the radial component of the coil magnetic field drives the armature and flight package forward.

In order to propel the armature continuously forward, each coil must be energized synchronously with the armature. This is accomplished by laser ranging on the armature and computer control of the firing circuit. The strength of the magnetic field seen by the armature is a sine function with quarter wavelength equal to about half the armature length. This wave is nearly frozen in the rest frame of the armature (although it is made to drift 
forward slowly by advancing the timing of the coils slightly). This operational technique reduces oscillating currents on the surface of the armature that would excessively heat it. It prevents large swings in magnetic fields that would induce electromagnetic pulses and problems for the payload. And finally, it reduces the voltage that is needed to drive the coils since the rise time is based on armature length..

A hypervelocity coilgun facility concept was developed for launching 100-kg satellites into orbits from 200 to $500 \mathrm{~km}$ altitude, into orbital planes inclined from $60^{\circ}$ to $80^{\circ}$ relative to the equator (Lipinski, et al 1991). Figure 2 is a schematic drawing of the launcher facility for $100 \mathrm{~kg}$ payloads launched at initial velocity of $6 \mathrm{~km} / \mathrm{s}$ at $25^{\circ}$ inclination. The facility consists of a coilgun launcher, the associated support buildings, energy storage system, launch packages, launcher support systems, and the control and monitoring systems.

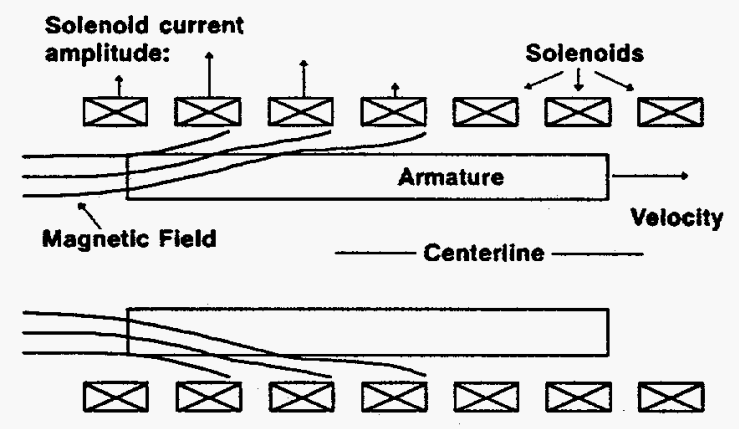

FIGURE 1. Cross-section of a cylindrical armature inside short solenoidal coils in a coilgun.

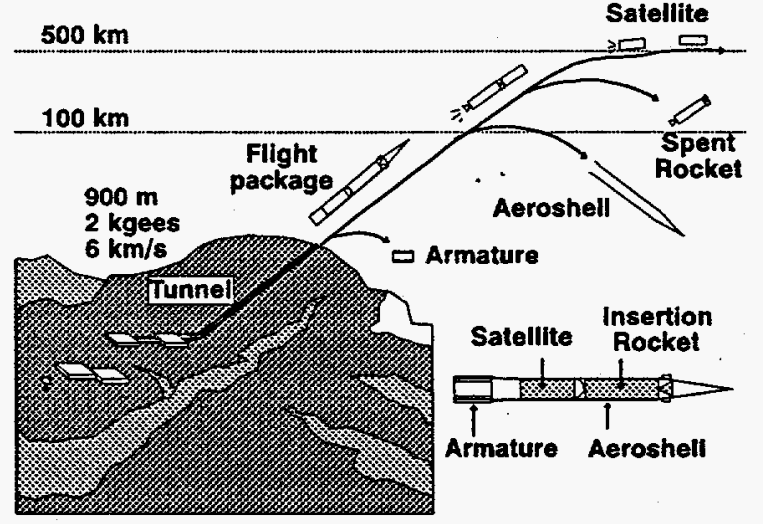

FIGURE 2. Overview of the hypervelocity coilgun launcher concept.

The coilgun pushes a flight package through an evacuated flyway tube to an exit velocity of $6 \mathrm{~km} / \mathrm{s}$. A thin foil breakaway window is located at the exit. The flight package consists of the satellite, an orbital insertion rocket, guidance, and an aeroshell, and is pushed through the coilgun by an armature. After launch, the armature is separated, slows and falls to the earth within a few miles because of its poor aerodynamic shape. The flight package is designed for atmospheric penetration and easily coasts through the atmosphere. The aeroshell protects the package from atmospheric heating, and then is petaled open and ejected. Once petaled open, the pieces of the aeroshell are much less robust against atmospheric heating and thus burn up upon re-entry. The insertion rocket then ignites and circularizes the orbit of the satellite. The rocket detaches from the satellite and makes a final small braking burn to assure that it reenters the atmosphere. There is no excess debris generated because all the components are designed to re-enter and burn in the atmosphere.

The coils in the launcher are each fired by a computer based on a real-time assessment of the location of the launch package. In experiments with a $1 \mathrm{~km} / \mathrm{s}$ launcher at Sandia (Kaye, et al 1994), this sense and fire control system was based on a laser range-finding beam injected through the gun to determine the location of the launch package. A benefit of this real-time sensing and firing technique is the ability to accurately control the exit velocity of the flight package.

Each coil has its own capacitor bank, so the energy to be imparted to the launch package is distributed along the gun and enters laterally, rather than only at the breech as with a railgun. This feature aids in reducing wear and also enhances safety because of reduced energy concentrations. Since the launcher is modular, the launcher pieces can be produced in large numbers, which will reduce their cost and risk. Maintenance of a damaged section or coil also is simplified by this modularity.

Table 1 summarizes the technical specifications for this launcher. The launcher is assumed to provide an initial velocity of $6 \mathrm{~km} / \mathrm{s}$ at the exit, with a solid-propellant rocket providing an additional $3.6 \mathrm{~km} / \mathrm{s}$ increment for orbit circularization. Each launch requires a kinetic energy of 32.4 GJ. At an energy efficiency of $50 \%$, this requires an 
electrical energy of $65 \mathrm{GJ}$. The energy must be delivered in about 0.38 seconds, for an average power of $170 \mathrm{GW}$. This power is provided from high energy capacitors, which are charged over about 3 minutes, at an average power of $360 \mathrm{MW}$. This charging power can be provided by a battery farm that is charged at a reduced power level over a time period of hours.

TABLE 1. Technical Specification for the Baseline Launcher.

\begin{tabular}{|l|c|}
\hline Launch velocity & $6 \mathrm{~km} / \mathrm{s}$ \\
\hline Launch tube length & $960 \mathrm{~m}$ \\
\hline Average acceleration & 2 kilogees \\
\hline Peak acceleration & $2.4 \mathrm{kilogees}$ \\
\hline Launch duration & $0.38 \mathrm{~s}$ \\
\hline Inclination & $25^{\circ}$ \\
\hline Number of coils & 9000 \\
\hline Coil length & $0.10 \mathrm{~m}$ \\
\hline Coil inner diameter & $0.79 \mathrm{~m}$ \\
\hline Coil turns at muzzle & 1 \\
\hline Peak magnetic field & $22.4 \mathrm{~T}$ \\
\hline Field rise length & $0.60 \mathrm{~m}$ \\
\hline Peak voltage & $56 \mathrm{kV}$ \\
\hline Peak current & $1782 \mathrm{kA}$ \\
\hline Launch package mass & $1820 \mathrm{~kg}$ \\
\hline Flight package mass & $1220 \mathrm{~kg}$ \\
\hline Armature mass & $600 \mathrm{~kg}$ \\
\hline Armature diameter & $0.72 \mathrm{~m}$ \\
\hline Electrical efficiency & $50 \%$ \\
\hline Final kinetic energy & $32.4 \mathrm{GJ}$ \\
\hline Initial stored energy & $64.8 \mathrm{GJ}$ \\
\hline
\end{tabular}

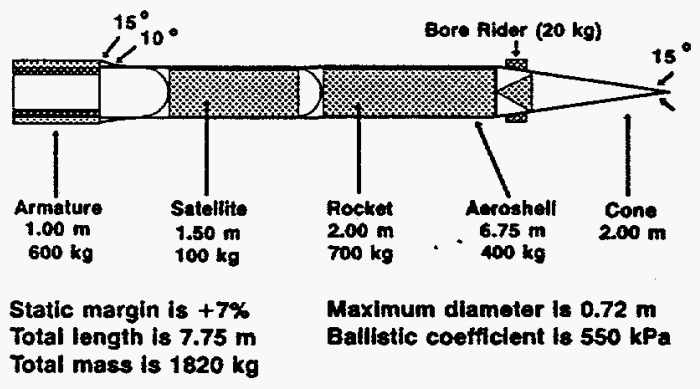

FIGURE 3. Baseline launch package configuration

\section{LAUNCH PACKAGE ISSUES AND REQUIREMENTS}

The baseline launch package is shown in Figure 3. The launch package consists of everything leaving the electromagnetic launcher: the armature, aeroshell, orbital insertion rocket, satellite, and nose bore-rider (sabot). The flight package is the launch package minus the armature and the bore-rider. The flight package is $1200 \mathrm{~kg}$, the armature is $600 \mathrm{~kg}$, and the bore-rider is $20 \mathrm{~kg}$. Flight stability of the launch vehicle is achieved by either passive or active means. Having passive stability, which cannot be achieved with rockets, is desirable, in that the inherent stability of the vehicle would reduce the uncertainty in trajectory, and could reduce the complexity of launch vehicle control and safety assurance. In order to achieve passive stability (i.e., a static margin of at least $7 \%$ ), the heavier and denser masses must be near the front of the package, as shown in Figure 3. Since the satellite has a relatively low density, it is placed behind the insertion rocket. The forward section of the vehicle must be a conical or ogive shape for aerodynamic drag reduction. A hollow frustum or a large flare is needed at the tail of the package to move the center of pressure behind the center of mass.

A concern for all forms of gun launch is the high acceleration. The satellite and the flight package both must be acceleration-hardened to withstand about a thousand times the force of gravity (one kilogee). However, this can be done by proven techniques such as tying down loose wires, potting electronics in plastic, avoiding cantilevered elements, and making the structure as compact as possible. Military shells are trending toward greater complexity and already have demonstrated the ability to be hardened against acceleration at levels of more than 10 kilogees.

Hypervelocity transit through the lower atmosphere requires an ablative heat shield (Lipinski, et al 1991). The heat loading on the aeroshell during the flight through the atmosphere was determined by experimentally validated codes used at Sandia (Blackwell and Kaestner 1970). These codes were then used to determine the appropriate 
thickness of heat shield needed. The highest temperature experienced by the outside of the rocket and payload is $30^{\circ}$ C. This temperature is reached in about 35 seconds.

\section{TRADE-OFF STUDY FROM THE BASELINE CONFIGURATION}

In this section, we evaluate the performance of the electromagnetic launcher over the 100-1000 kg payload range, varying the exit velocity over the range for launch velocities 1 to $6 \mathrm{~km} / \mathrm{s}$. The following analytical approach is used. (1) The velocity lost from atmospheric drag is first calculated for the given initial launch velocity, using an estimated hypersonic drag derived from the vehicle shape (Lipinski, et al 1991). (2) Additional equations yield the velocity and altitude at the apogee of the ballistic arc, and from this the incremental velocity needed to attain the desired orbital altitude is calculated. (3) This delta-v is used to size the rocket booster, using an assumed solid-motor of 290 seconds specific impulse. (4) Aeroshell mass is calculated on the basis of the size of the vehicle and the ablative thickness required for transit through the atmosphere. (5) The mass of the armature is calculated from the vehicle size, the thickness needed to support the induced eddy currents, and the limits of structural strength of the material. (6) These calculations thus give the mass of the complete launch vehicle. The kinetic energy is calculated from the launch velocity and vehicle mass. The conversion efficiency from electrical energy to kinetic energy is assumed to be $50 \%$, a reasonable number from our experience for scaling to high launch velocity and large-diameter coils. (7) Acceleration through the launcher will be nearly uniform. The average power is calculated from the total electrical energy and the launch time interval. The peak electrical power will be about $20 \%$ more than the average, and occurs at the last stages of acceleration. (8) Incremental launch costs were based on the cost of booster rocket (Morton Thiokol 1989), armature, and aeroshell (based on material and fabrication costs). (9) The facility cost was scaled from the cost estimates made for the capacitor system point design discussed in the previous section. This scaling assumed that energy costs and power costs from Table 2 would scale linearly with energy and power, and the fixed facility costs and R\&D would be independent of energy or power over this range.

Figures 4-9 summarize the results of the trade-off study. A fixed launcher length of $2 \mathrm{~km}$ is assumed, so a lower launch velocity implies a lower acceleration. Note that the launch vehicle kinetic energy is in the range of 20 to $130 \mathrm{GJ}$ and is not a strong function of the launch velocity. This is due to the fact that more rocket booster mass must be launched at reduced launch velocity Vehicle acceleration varies from $30-1000$ gees. The average launch electrical power varies from a low of $40 \mathrm{GW}$ for $1 \mathrm{~km} / \mathrm{s}$ and $100 \mathrm{~kg}$ payload, to a high of $400 \mathrm{GW}$ at $6 \mathrm{~km} / \mathrm{s}$ and $1000 \mathrm{~kg}$ payload. Incremental launch costs are in the range of $\$ 1000-\$ 6,000 / \mathrm{kg}$, with the lower costs coming from the higher initial launch velocity.

\section{CONCLUSIONS}

For a satellite payload of 100-1000 kg, the launcher electrical energy requirement is $40-260 \mathrm{GJ}$, and the peak power requirement is $20-400 \mathrm{GW}$. At these power levels, a system of energy storage and fast switching will be needed. In the baseline resistive-coil concept, the temporary energy storage is accomplished with batteries and capacitors. Energy from the capacitors is switched into the propulsion coils on the microsecond time scale. With 9000 propulsion coils, each coil is energized with $4 \mathrm{MJ}$ of energy. The technology for such capacitor-coil combinations is available now, and has been demonstrated in high-velocity launcher experiments at the level of 60 $\mathrm{kJ}$ electrical energy. The capacitor cost is a major portion of the total launcher cost. The use of superconducting coil energy storage could offer the potential of significantly reducing the launcher cost, but further technology development would be needed to perfect superconducting coil switching (Turman, et al, 1994).

The launcher energy requirement is a weak function of launch velocity over the range from $1-6 \mathrm{~km} / \mathrm{s}$, because the orbital insertion rocket mass increases as launch velocity is reduced. Facility cost is also a weak function of launch velocity, since facility cost is dominated by the energy requirement. For $500 \mathrm{~kg}$ launch capability, the total facility cost is estimated to be about $\$ 4.5 \mathrm{~B}$. The incremental launch cost increases as launch velocity is reduced, driven by the increased mass and cost of the booster rocket. The incremental cost for $500 \mathrm{~kg}$ at $6 \mathrm{~km} / \mathrm{s}$ is about $\$ 1300 / \mathrm{kg}(\$ 600 / \mathrm{lb})$, and at $3 \mathrm{~km} / \mathrm{s}$ it is about $\$ 2000 / \mathrm{kg}(\$ 900 / \mathrm{b})$. This compares favorably to present-day smallsatellite launch costs of some $\$ 10,000-\$ 40,000 / \mathrm{kg}$. Assuming a total of 2000 launches, the total launch cost will be about $\$ 6500 / \mathrm{kg}$, or $\$ 3000 / \mathrm{b}$. 
With a $2 \mathrm{~km}$ launcher, the peak acceleration is 30-1000 gee's. The payload must be hardened to this acceleration, but such hardening is within the state-of-the art for hardened military weapon electronics. Launch at high velocity in the lower atmosphere introduces a severe aerodynamic load on the vehicle, and an ablative aeroshell is required. The cost and weight of this aeroshell can be reduced by choosing a moderate launch velocity of 3 or $4 \mathrm{~km} / \mathrm{s}$.

The lower incremental launch cost, ease, and simplicity of the totally reusable launcher and drastically reduced chemical propellants offer an attractive potential for launching satellites with missions that require a large number of launches. Further development work is required to determine in greater detail the optimum design for the launcher, including the proper choice for power technology.

\section{Acknowledgements}

This work was supported by the United States Department of Energy under Contract DE-AC04-94AL85000.

\section{References}

Andrews, A., Ed., Commercial Space Transport Study Final Report, Boeing Corporation, Seattle, WA, developed by Boeing, General Dynamics, Lockheed, Martin Marietta, McDonnell Douglas, and Rockwell, April 1994.

Blackwell, B. F., and P. C. Kaestner, 1970, "Operation Instructions for Charring Material Ablation Code," SC-DR70-140, Sandia national laboratories, Albuquerque, NM.

Kaye, R. J., I. R. Shokair, R. W. Wavrik, J. F. Dempsey, W. E. Honey, K. J. Shimp, G. M. Douglas, 1994, "Design and Evaluation of Coils for a $50 \mathrm{~mm}$ Diameter Induction Coilgun Launcher," presented at the 7th Symposium on Electromagnetic Launch Technology, San Diego, CA, April 20-24, 1994.

Langreth, R., "Asteroid Watchers", Popular Science, pp 76-82, September 1992.

Lipinski, R. J., S. G. Beard, J. D. Boyes, E. C. Cnare, M. Cowan, B. W. Duggin, R. J. Kaye, D. E. Outka, D. L. Potter, M. M. Widner, C. C. Wong, 1991, Hypervelocity Gun Report: Electromagnetic Coilgun, Sandia Report SAND911600.

Morton Thiokol, 1989, "Rocket Motor Catalogue,", Elkton, MD.

Spent Fuel Management and Transport 1994, Nuclear Engineering International Magazine, London (1994)

Turman, B. N., R. J. Lipinski, M. R. Palmer, E. M. W. Leung, 1994, "Co-Axial Geometry Electromagnetic Launch to Space," AIAA Space Programs and Technologies Conference, Huntsville, AL, September 27-29, 1994.

Ulrich,P., Ed., Draft Environmental Impact Statement for the Cassini Mission, NASA/HQ, Washington, DC (1994)

Wilson, A., Ed., Jane's Space Directory 1993-1994, Jane's Information Group, Surrey, UK (1993).

\section{DISCLAIMER}

This report was prepared as an account of work sponsored by an agency of the United States Government. Neither the United States Government nor any agency thereof, nor any of their employees, makes any warranty, express or implied, or assumes any legal liability or responsibility for the accuracy, completeness, or usefulness of any information, apparatus, product, or process disclosed, or represents that its use would not infringe privately owned rights. Reference herein to any specific commercial product; process, or service by trade name, trademark, manufacturer, or otherwise does not necessarily constitute or imply its endorsement, recommendation, or favoring by the United States Government or any agency thereof. The views and opinions of authors expressed herein do not necessarily state or reflect those of the United States Government or any agency thereof. 


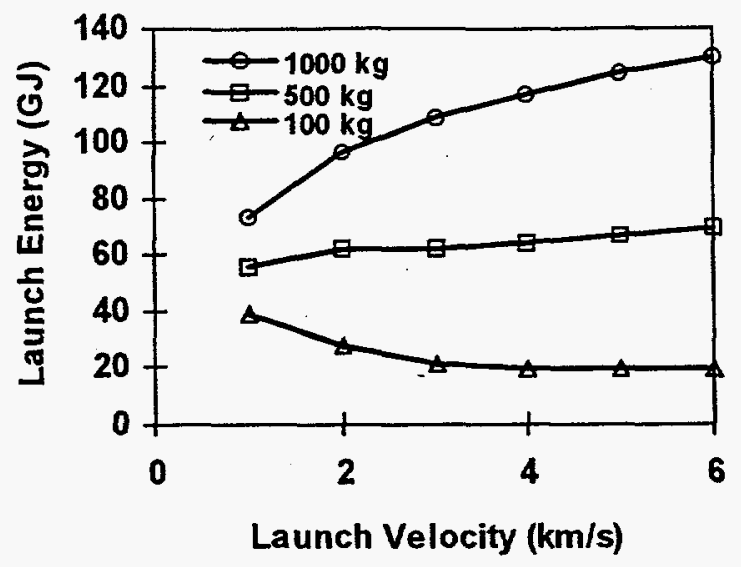

FIGURE 4. Kinetic energy of launch package.

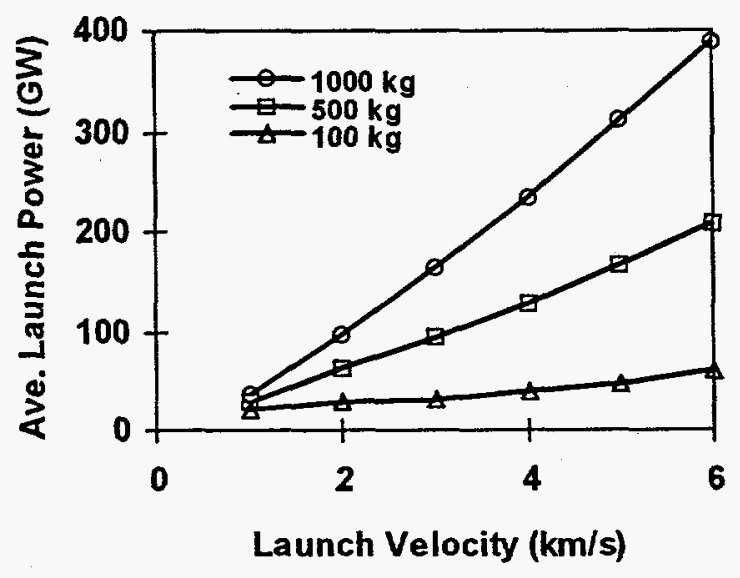

FIGURE 5. Average power during launch.

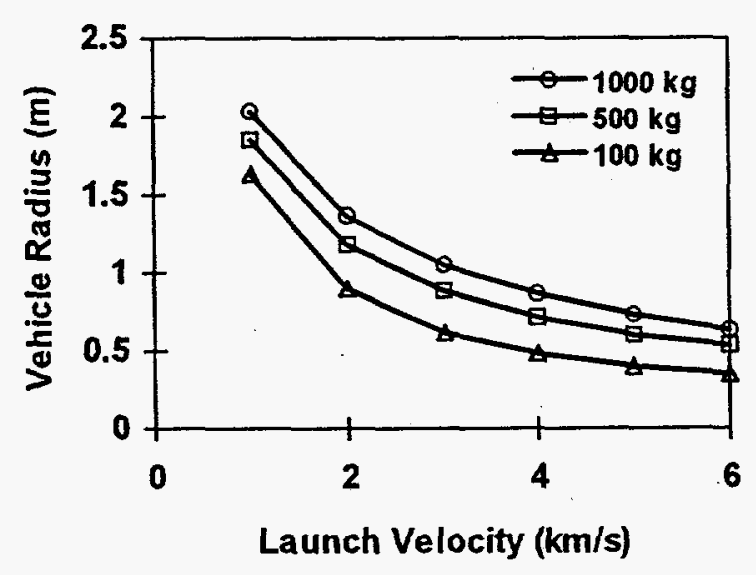

FIGURE 6. Radius of launch package.

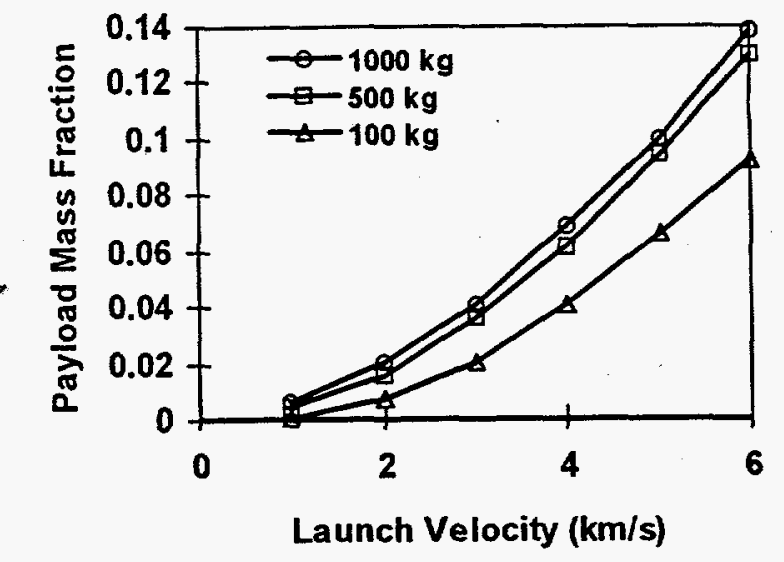

FIGURE 7. Satellite mass divided by flight-package mass.

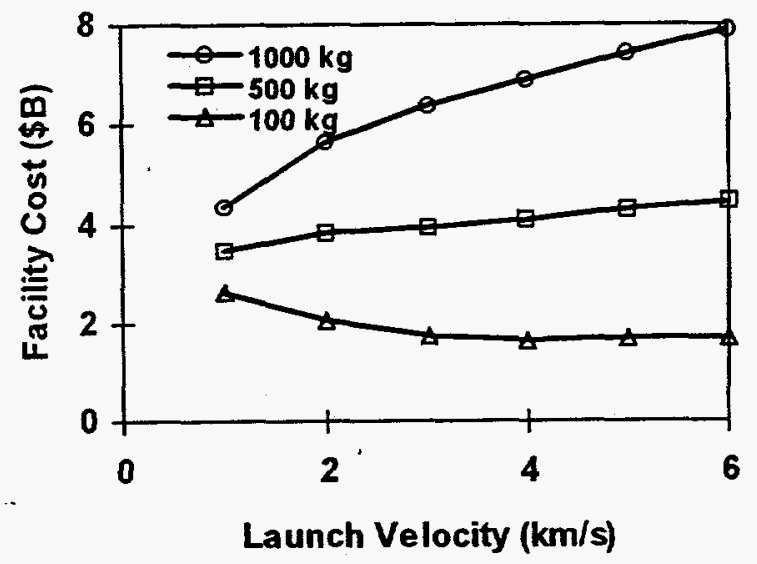

FIGURE 8 Cost of launcher facility.

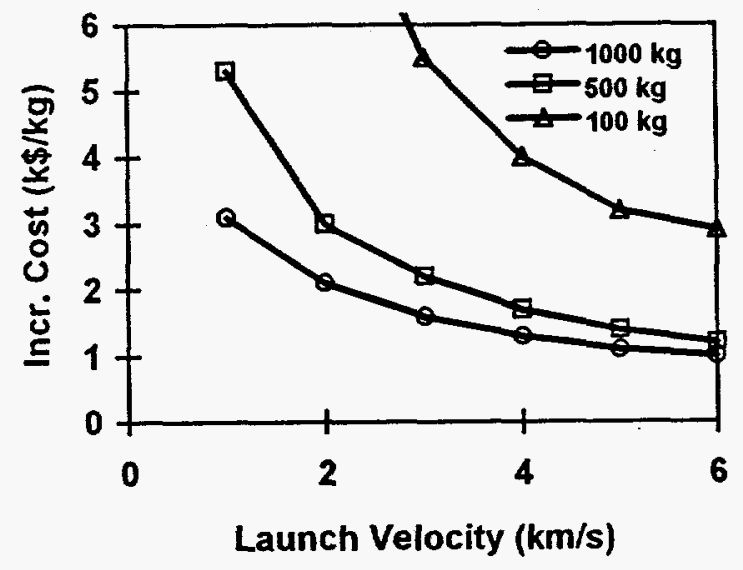

FIGURE 9. Incremental launch cost. 